\title{
N-Acetylcysteine breaks resistance to trastuzumab caused by MUC4 overexpression in human HER2 positive BC-bearing nude mice monitored by ${ }^{89} \mathrm{Zr}-T r a s t u z u m a b$ and ${ }^{18}$ F-FDG PET imaging
}

\author{
Zéna Wimana ${ }^{1,2}$, Geraldine Gebhart ${ }^{1}$, Thomas Guiot ${ }^{1}$, Bruno Vanderlinden ${ }^{1}$, Denis \\ Larsimont ${ }^{3}$, Gilles Doumont ${ }^{4}$, Gaetan Van Simaeys ${ }^{4}$, Serge Goldman ${ }^{4}$, Patrick \\ Flamen $^{1}$ and Ghanem Ghanem ${ }^{1,2}$ \\ ${ }^{1}$ Nuclear Medicine Department, Institut Jules Bordet, Université Libre de Bruxelles, Brussels, Belgium \\ ${ }^{2}$ Laboratory of Oncology and Experimental Surgery, Institut Jules Bordet, Université Libre de Bruxelles, Brussels, Belgium \\ ${ }^{3}$ Pathology Department, Institut Jules Bordet, Université Libre de Bruxelles, Brussels, Belgium \\ ${ }^{4}$ Center for Microscopy and Molecular Imaging (CMMI), Université Libre de Bruxelles, Brussels, Belgium
}

Correspondence to: Zéna Wimana, email: zena.wimana@bordet.be

Keywords: HER2, NAC, trastuzumab, resistance, immunoPET

Received: September 30, 2016

Accepted: March 30, 2017

Published: April 10, 2017

Copyright: Wimana et al. This is an open-access article distributed under the terms of the Creative Commons Attribution License 3.0 (CC BY 3.0), which permits unrestricted use, distribution, and reproduction in any medium, provided the original author and source are credited.

\section{ABSTRACT}

Trastuzumab remains an important drug in the management of human epidermal growth factor receptor 2 (HER2) overexpressing breast cancer (BC). Several studies reported resistance mechanisms to trastuzumab, including impaired HER2-accessibility caused by mucin 4 (MUC4). Previously, we demonstrated an increase of Zirconium89-radiolabeled-trastuzumab ( ${ }^{89} \mathrm{Zr}$-Trastuzumab) accumulation when MUC4overexpressing $\mathrm{BC}$-cells were challenged with the mucolytic drug $\mathrm{N}$-Acetylcysteine (NAC). Hereby, using the same approach we investigated whether tumor exposure to NAC would also enhance trastuzumab-efficacy.

Dual SKBr3 (HER2+/MUC4-, sensitive to trastuzumab) and JIMT1 (HER2+/ MUC4+, resistant to trastuzumab) HER2-BC-bearing-xenografts were treated with trastuzumab and NAC. Treatment was monitored by molecular imaging evaluating HER2-accessibility/activity ( ${ }^{89} \mathrm{Zr}$-Trastuzumab HER2-immunoPET) and glucose metabolism ( ${ }^{18} \mathrm{~F}-\mathrm{FDG}-\mathrm{PET} / \mathrm{CT}$ ), as well as tumor volume and the expression of key proteins.

In the MUC4-positive JIMT1-tumors, the NAC-trastuzumab combination resulted in improved tumor-growth control compared to trastuzumab alone; with smaller tumor volume/weight, lower 18F-FDG uptake, lower \%Ki67 and pAkt-expression. NAC reduced MUC4-expression, but did not affect HER2-expression or the trastuzumabsensitivity of the MUC4-negative SKBr3-tumors.

These findings suggest that improving HER2-accessibility by reducing MUC4masking with the mucolytic drug NAC, results in a higher anti-tumor effect of trastuzumab. This provides a rationale for the potential benefit of this approach to possibly treat a subset of HER2-positive BC overexpressing MUC4.

\section{INTRODUCTION}

The Human epidermal growth factor receptor 2 (HER2) transmembrane oncoprotein is overexpressed in $20-30 \%$ of breast cancer (BC) patients [1, 2]. HER2 overexpression in $\mathrm{BC}$ has been associated with an aggressive biological behavior, translated into shorter disease-free interval and overall survival in patients with early and advanced disease states $[3,4]$. Trastuzumab, a recombinant, humanized monoclonal antibody $(\mathrm{mAb})$ was the first clinically approved anti-HER2 therapy. It specifically binds to HER2 on the C-terminal portion of 
the extracellular domain (ECD) near the juxtamembrane region in domain IV of the HER2 receptor.

The proposed mechanisms of action of trastuzumab are multiple. It's most well-known and crucial mechanism of action is the inhibition of the PI3K/Akt pathways. Trastuzumab interferes with HER2 activation and so results in the suppression of Akt phosphorylation [5, 6].

Trastuzumab used in addition to standard chemotherapy has been shown to improve treatment outcome of early as well as metastatic stage in HER2positive $\mathrm{BC}[7,8]$. However, despite this success, responses to trastuzumab have been hampered by several resistances mechanisms $[9,10]$. One of these is the overexpression of high molecular weight membraneanchored mucin MUC4 [9].

MUC4 is overexpressed in 30-95\% of all types of $\mathrm{BC}$ as well as lymph nodes metastases and tumor vascular emboli. MUC4 has been correlated with progression and higher tumor grade [11-13]. This large glycoprotein can considerably hinder the accessibility and hence the binding of trastuzumab to HER2 ectodomain, thereby impairing efficient trastuzumab-based treatment [14, 15]. MUC4 has also been postulated to interact closely with HER2 to form a ligand-receptor type intramembrane complex. Herein, it has been shown to operate as a ligand/modulator of HER2 activation by inducing the phosphorylation of HER2 on tyr1248 [12, 16-19].

In a previous molecular imaging study, HER2 receptor impaired accessibility by MUC4 in BC was shown to be appropriately assessed by in vivo molecular imaging using PET and Zirconium-89 radiolabeled trastuzumab ( ${ }^{89} \mathrm{Zr}$-Trastuzumab). Importantly, mucolytic treatment N-Acetylcysteine (NAC) restored the impaired HER2 accessibility caused by MUC4, and consequently enhanced the binding and uptake of ${ }^{89} \mathrm{Zr}$-Trastuzumab in vitro and in vivo in a MUC4-expressing HER2-positive BC xenograft mouse model [19].

NAC is known to be a safe, well-tolerated, welldocumented and inexpensive drug $[18,19]$. Furthermore, it is more effective than any other mucolytic drug and has therefore been the most widely used [20]. NAC presents an acetyl group promoting its binding to the cell membrane and a free thiol group able to reduce intra- or intermolecule disulfide bonds between cysteine residues of mucins [18, 20], leading to reduced masking of HER2 [19]. Of, note NAC has also been reported to indirectly inhibit mTOR, downstream of the PI3K/akt pathway [23].

In the present study, we hypothesized that MUC4related resistance to trastuzumab can be overcome through the use of a mucolytic drug, by improving the accessibility of the drug to HER2 and hence achieve a better anti-tumor effect. This approach was evaluated in a dual JIMT1 (HER2+/MUC4+; resistant to trastuzumab) and SKBr3 (HER2+/MUC4-; control sensitive to trastuzumab) HER2 human BC-bearing xenograft model by molecular imaging techniques ${ }^{89} \mathrm{Zr}$-Trastuzumab HER2-immunoPET and ${ }^{18} \mathrm{~F}-\mathrm{FDG}$ PET-CT; as well as measurement of tumor volume and pathological examination (Figure 1).

\section{RESULTS}

\section{Mucolytic drug NAC enhances HER2 accessibility for trastuzumab in MUC4- overexpressing tumors as shown on ${ }^{89} \mathrm{Zr}$ - Trastuzumab immunoPET}

Baseline ${ }^{89} \mathrm{Zr}$-Trastuzumab PET imaging at 6 days post injection revealed tumor uptake in all mice in both NAC and control group. ${ }^{89} \mathrm{Zr}$-Trastuzumab also showed visible uptake in the liver and bones. Image analysis demonstrated a statistically significant increase in radiotracer uptake, represented by $\% \Delta \mathrm{SUV}_{\max }(33.7 \pm 7.4 \%$, $p<0.001$ ) of MUC4 overexpressing JIMT1 tumors in mice treated with NAC $(2.55 \pm 0.05)$ compared to untreated controls $(2.17 \pm 0.06)$. In contrast, no significant differences were observed in ${ }^{89} \mathrm{Zr}$-Trastuzumab uptake for MUC4negative $\mathrm{SKBr} 3$ tumors implanted in the same animal (NAC: $2.40 \pm 0.06$ vs. controls: $2.35 \pm 0.07$ ) (Figure 2).

\section{NAC supplementation improves the antitumor activity of trastuzumab in MUC4-overexpressing tumors}

\section{Tumor volume monitoring}

Longitudinal assessment of tumor growth revealed an increase in subcutaneous tumor volume in all tumor types and all treatment arms with different tumorgrowth-rates (Figure $3 \mathrm{~A}$ and $3 \mathrm{~B}$ ). At the end of the treatment period and in the trastuzumab-sensitive SKBr3 tumors, trastuzumab significantly induced slower cell doubling times compared to untreated controls, with or without NAC (CT=32.3 days vs $\mathrm{CS}=20.3$ and $\mathrm{NT}=30.1$ vs $\mathrm{NS}=20.8$, all $p<0.001)$ and consequently smaller tumor volumes $\left(\mathrm{CT}=0.60 \pm 0.10 \mathrm{~cm}^{3}\right.$ vs $\mathrm{CS}=1.33 \pm 0.27$, $\mathrm{NT}=0.60 \pm 0.13$ vs NS$=1.41 \pm 0.27$, both $p<0.001)$. In contrast, in the trastuzumab-resistant JIMT1, inhibition of tumor growth was only obtained when trastuzumab was combined with NAC $(\mathrm{NT}=33.9$ days vs $\mathrm{CT}=21.0$, $\mathrm{NS}=21.7$ and $\mathrm{CS}=21.6$, all $p<0.001)$ resulting in smaller tumor volume in the NT group (NT=0.69 $\pm 0.10 \mathrm{~cm}^{3}$ vs CT $=1.52 \pm 0.22, \mathrm{NS}=1.43 \pm 0.18$ and $\mathrm{CS}=1.37 \pm 0.20$, all $p<0.001)$.

These results were corroborated by in vivo measurements on $\mathrm{CT}$ as well as confirmed by tumor weight at dissection (Supplementary Figure 1).

\section{${ }^{18}$ F-FDG PET-CT assessment}

After treatment completion, the effects of trastuzumab treatment on tumor metabolism were assessed through changes in ${ }^{18} \mathrm{~F}$-FDG uptake $\left(\% \Delta \mathrm{SUV}_{\max }\right)$. 


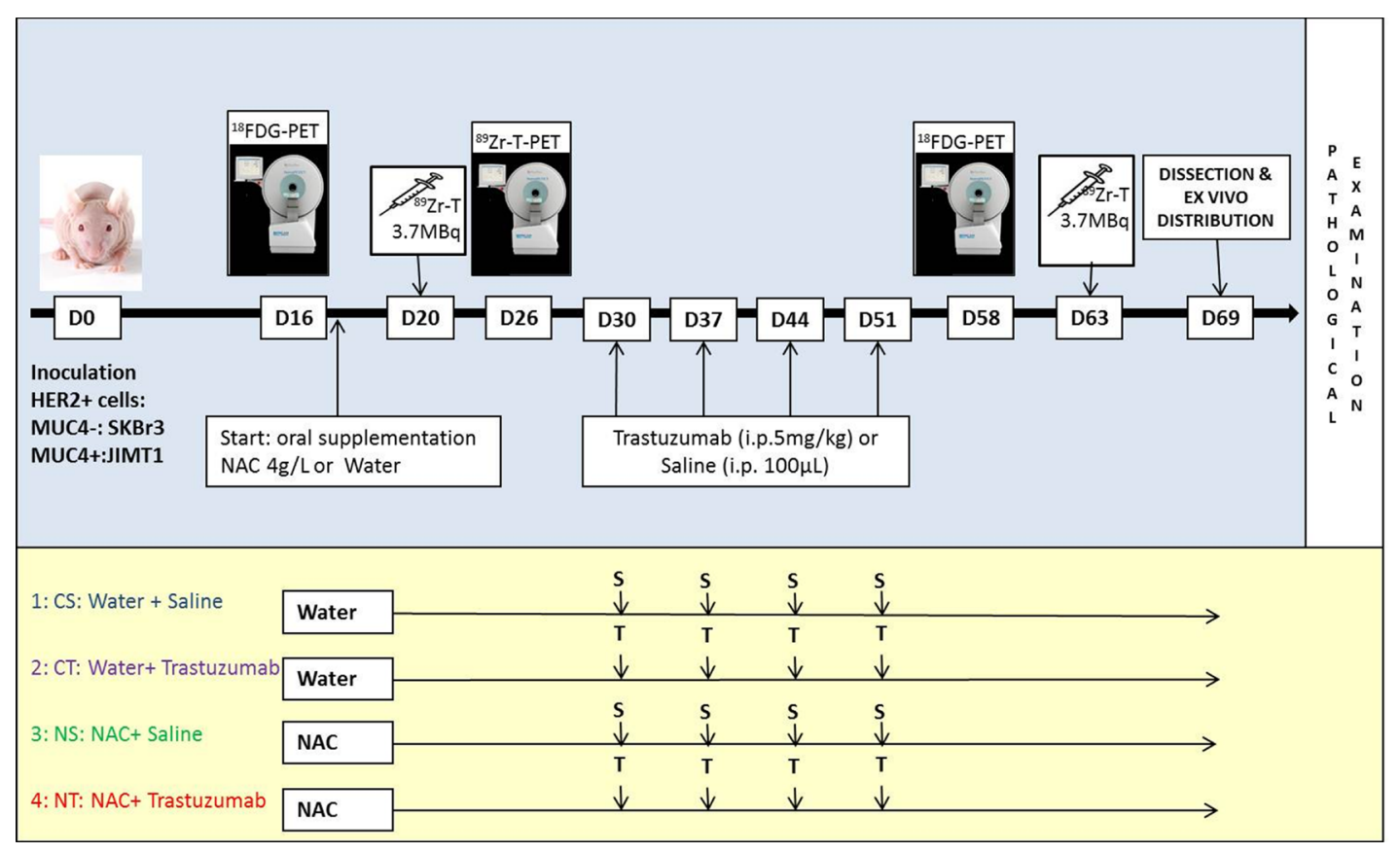

Figure 1: Timeline of the animal experimentation. Athymic nu/nu female mice were inoculated subcutaneously on the right posterior leg with SKBr3 (HER2+/MUC4-) cells and on the left with JIMT1 (HER2+/MUC4+) cells. Imaging and treatments were initiated two weeks after inoculation when tumors reached approximately $0.5 \mathrm{~cm}^{3}$. Mice were randomized to four different groups: (1) the CS group receiving sweetened drinking water and i.p. saline injections $(n=10),(2)$ the CT group receiving sweetened drinking water and trastuzumab injections (i.p., $5 \mathrm{mg} / \mathrm{kg}(n=10)$, (3) the NS group receiving sweetened drinking water supplemented with NAC and saline i.p. injections $(n=9)$, and (4) the NT group receiving sweetened drinking water supplemented with NAC and trastuzumab injections (i.p., $5 \mathrm{mg} / \mathrm{kg})(n=$ 10). Imaging studies were conducted using a $\mu$ PET-CT and each mouse was scanned three times, with an ${ }^{18} \mathrm{~F}-\mathrm{FDG}$ and ${ }^{89} \mathrm{Zr}$-Trastuzumab PET-CT before treatment and an ${ }^{18} \mathrm{~F}$-FDG PET-CT post treatment. Images were recorded for ${ }^{18} \mathrm{~F}-\mathrm{FDG}$ at $1 \mathrm{~h}$ and ${ }^{89} \mathrm{Zr}$-Trastuzumab 6 days after injection respectively. After the last scan, animals were euthanized and an ex-vivo body distribution study was performed. A pathological examination was also conducted on a subset of animals from each cohort with immunostaining of HER2, MUC4, pAkt and Ki67.

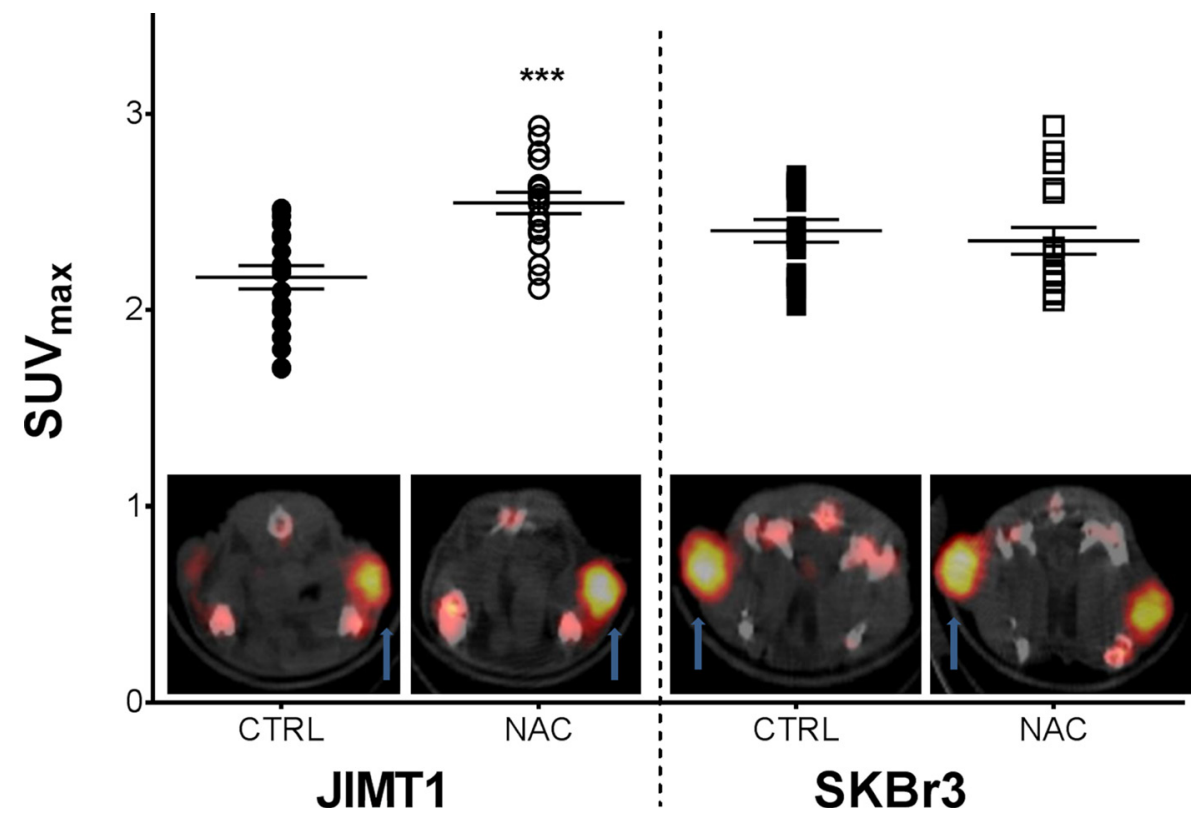

Figure 2: Mucolytic drug NAC enhances ${ }^{89} \mathrm{Zr}$-Trastuzumab uptake in MUC4 overexpressing JIMT1 tumors. Standardized maximum uptake of ${ }^{89} \mathrm{Zr}$-Trastuzumab in JIMT1 (HER2+/MUC4+; dot) and SKBr3 (HER2+/MUC4-; squares) tumors under NAC supplementation $(n=19)$ and control $(n=20)$ are shown in the graph with a ${ }^{89} \mathrm{Zr}$-Trastuzumab PET axial image representative of the tumor (arrow) uptake under NAC exposure (NAC) and control (CTRL). All data points and mean \pm SEM are shown, both expressed in $\mathrm{SUV}_{\text {max }}$ with $* * * p<0.001$. 
In the MUC4-overexpressing trastuzumab resistant JIMT1 tumors, tumor metabolic changes were observed exclusively in the treatment arm combining trastuzumab and NAC with a significantly lower $\% \Delta \mathrm{SUV}_{\max }(\mathrm{NT}=12.6 \pm 7.8 \%$ vs $\mathrm{CT}=78.6 \pm 10.6$, $\mathrm{NS}=62.1 \pm 12.1$ and $\mathrm{CS}=75.1 \pm 15.5$; all $p<0.01)$
(Figure 4B). Whereas in the control SKBr3 tumors, trastuzumab-based treatment led to a significant reduction of tumor activity compared to the respective controls and this independent of NAC supplementation $\left(\% \Delta \mathrm{SUV}_{\max }: \mathrm{CT}=29.2 \pm 7.1 \%\right.$ vs $\mathrm{CS}=72.5 \pm$ 12.5 and NT $=33.8 \pm 11.6$ vs NS $=75.7 \pm 12.6 \%$;
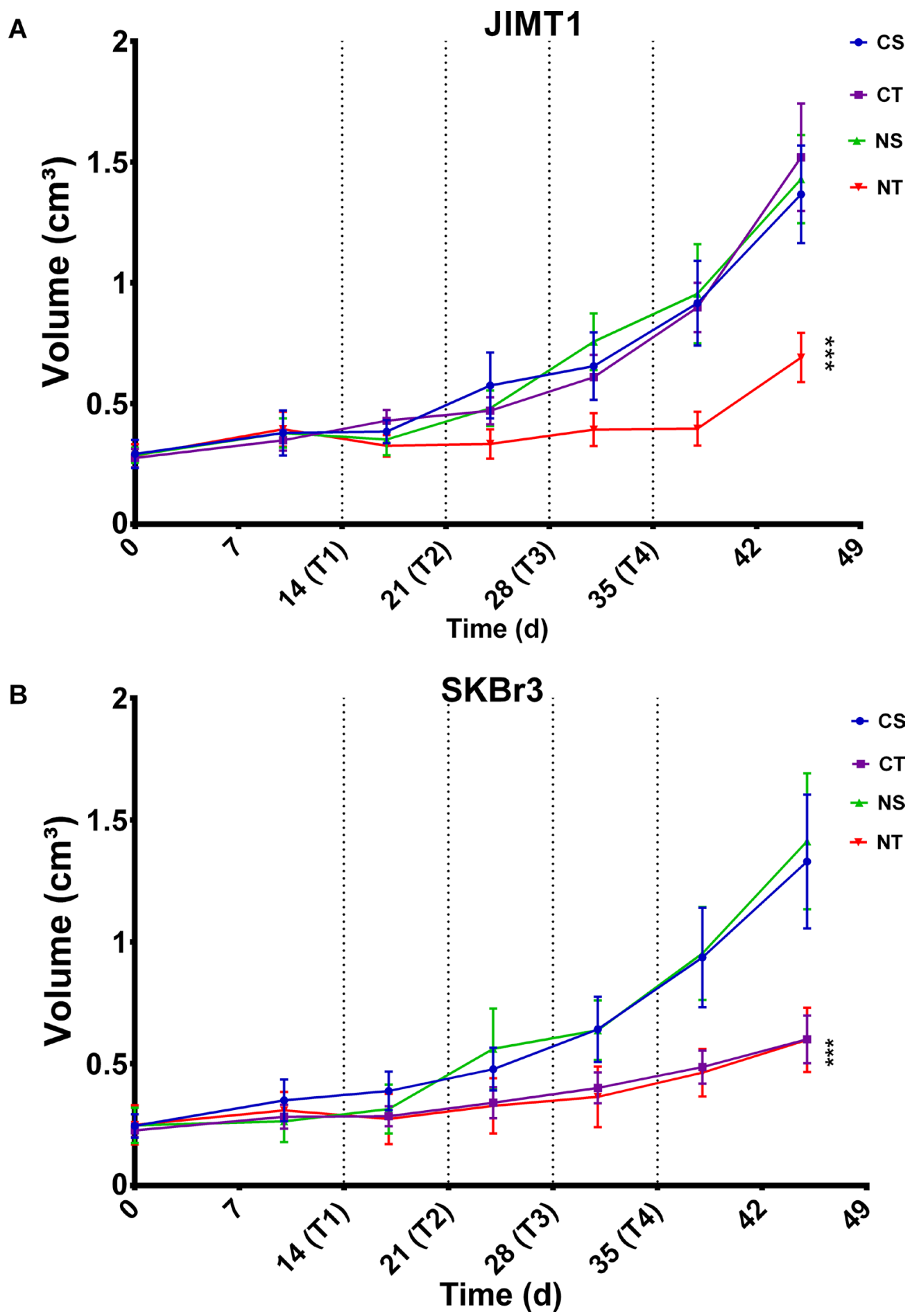

Figure 3: The combination of trastuzumab with NAC supplementation results in slower tumor growth. The effect of the different treatment on JIMT1 (HER2+/MUC4+) and SKBr3 (HER2+/MUC4) tumors in dual-tumor-bearing mice randomized to the four treatment arms CS (Control+Saline; blue, $n=10)$, CT (Control+Trastuzumab; purple, $n=10)$, NS (NAC + Saline; green, $n=9)$ and NT (NAC+Trastuzumab; red $n=10)$ is represented per methodologies as follows: Tumor growth of JIMT1 (A) and SKBr3 (B) tumors monitored through caliper measurements. Data are represented as mean $\pm \mathrm{SEM}$, expressed in $\mathrm{cm}^{3}$ for tumor volume, with $* * * p<0.001$. 
$p<0.001$ and $p<0.01$ ) (Figure 4C). Supplementation with NAC alone did not induce any effect on tumor metabolic changes in either tumor types compared to controls.

\section{Proliferation index Ki67 and activation of the Pi3K/Akt pathway}

In the MUC4-overexpressing trastuzumab resistant JIMT1 tumors, the percentage of Ki67 positive cells was decreased only in the NAC-trastuzumab combination arm compared to the other groups $(\mathrm{NT}=13.8 \pm 0.8 \%$ vs $\mathrm{CT}=25.6 \pm 2.7, \mathrm{NS}=26.3 \pm 1.5$ and $\mathrm{CS}=28.3 \pm 1.6$; $p<0.001$ ) (Figure 5). The pAkt expression levels of those JIMT1 tumors in the NT combination arm were lower as well $(\mathrm{NT}=4.5 \pm 0.5$ vs $\mathrm{CT}=8.3 \pm 0.5, \mathrm{NS}=8.3$ \pm 0.5 and $\mathrm{CS}=8.2 \pm 0.6 ; p<0.001$ ) (Figure 5A). In the control SKBr3 tumors, trastuzumab treatment, with or without NAC supplementation, resulted in a decrease in Ki67 positive tumor cells compared to the respective controls $(\mathrm{CT}=15.3 \pm 1.6 \%$ vs $\mathrm{CS}=26.7 \pm 1.8$ and $\mathrm{NT}=14.9 \pm 1.6$ vs $\mathrm{NS}=25.8 \pm 1.5 ; p<0.001$ and $p=0.028$ ) (Figure 5B). Also, the pAkt level were about twice lower in trastuzumab-treated $\mathrm{SKBr} 3$ tumors compared to the control group $(\mathrm{CT}=5.0 \pm 0.8$ vs $\mathrm{CS}=$ $9.2 \pm 0.4$ and $\mathrm{NT}=5.4 \pm 0.3$ vs NS $=9.5 \pm 0.3$; both $p<0.001$ ) (Figure 5B). Representative samples of the pathological examination of the Ki67 index and pAkt expression levels are shown in Supplementary Figure 2.

\section{Prolonged NAC supplementation does not alter ${ }^{89} \mathrm{Zr}$-Trastuzumab body distribution in tumor- bearing mice}

To assess the possible impact of prolonged supplementation of NAC on body distribution of

A
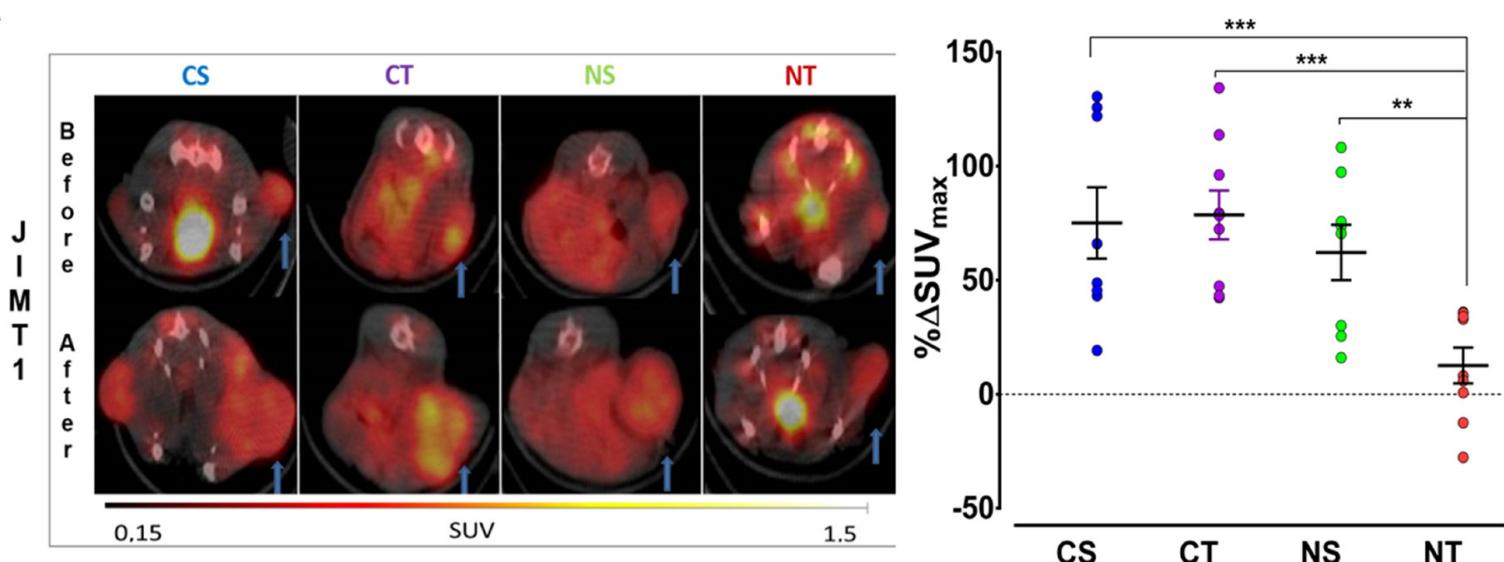

B
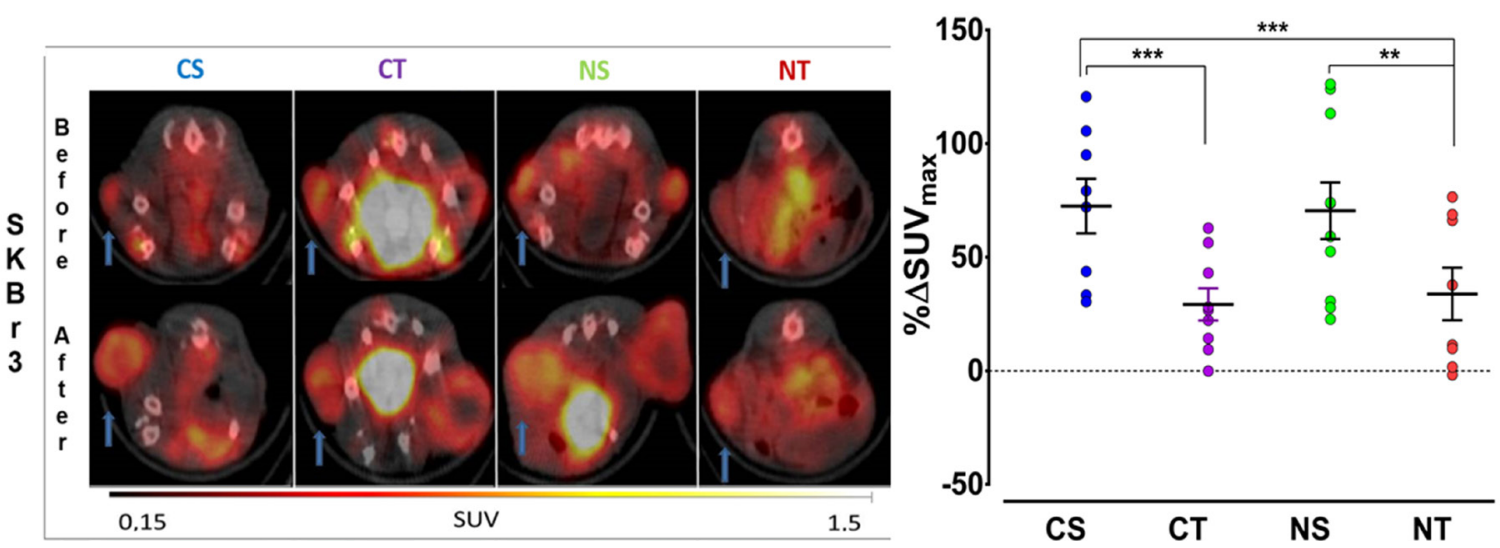

Figure 4: The combination of trastuzumab with NAC supplementation results in a lower ${ }^{18} \mathrm{~F}-\mathrm{FDG}$ uptake in trastuzumab resistant tumors. ${ }^{18} \mathrm{~F}-\mathrm{FDG}$ uptake of SKBr3 (HER2+/MUC4-) and JIMT1 (HER2+/MUC4+) tumors in dual-tumorbearing mice randomized to the four treatment arms CS (Control+Saline; blue, $n=10$ ), CT (Control+Trastuzumab; purple, $n=10$ ), NS (NAC+Saline; green, $n=9$ ) and NT (NAC+Trastuzumab; red $n=10$ ) is represented. (A) The baseline ${ }^{18}$ F-FDG uptake of JIMT1 and SKBr3 tumors preceding randomization is shown with future treatment group allocation. Representative ${ }^{18} \mathrm{~F}-\mathrm{FDG}$ PET/CT axial images(left) of the tumor (arrow) before and after treatment are shown together with the changes in ${ }^{18} \mathrm{~F}$-FDG uptake represented as percentage difference in $\mathrm{SUV}_{\max }\left(\% \triangle S U V_{\max }\right.$, right) for (B) JIMT1 and SKBr3 tumors in the different treatment arms. Data points as well as mean $\pm \mathrm{SEM}$ are shown. Data are expressed in $\mathrm{SUV}_{\max }$ for the baseline ${ }^{18} \mathrm{~F}-\mathrm{FDG}$ uptake or as the percentage difference in $\mathrm{SUV}_{\max }\left(\% \Delta S U V_{\max }\right)$ when comparing the effect of the different treatment arms; with $* * p<0.01$ and $* * * p<0.001$. 
${ }^{89} \mathrm{Zr}$-Trastutumab, organ radioactivity was measured after 60 days on NAC. High uptake occurred in all tumors, liver and spleen and was negligible in the brain as shown in Figure 6. Radioactivity accumulation in non-tumor as well as in the MUC4-negative SKBr3 tumor was not significantly altered by long term NAC exposure.

In the MUC4-positive JIMT1 tumors treated with NAC, a statistically significant higher radioactivity accumulation was observed compared to respective controls $(\mathrm{NS}=2.89 \pm 0.25$ vs $\mathrm{CS}=1.81 \pm 0.2$ and $\mathrm{NT}=2.53 \pm 0.28$ vs $\mathrm{CT}=1.78 \pm 0.16 ; p<0.001$ for both). Furthermore, treatment with trastuzumab (CT and NT) only resulted in a trend for lower ${ }^{89} \mathrm{Zr}$-Trastuzumab accumulation compared to their corresponding control arm (CS and NS).

\section{Comparison of HER2 expression, HER2 accessibility for trastuzumab metabolic response assessed by ${ }^{18}$ F-FDG PET}

Immunostaining for MUC4 showed overexpression in JIMT1 tumors, with lower MUC4 expression observed in the groups with NAC supplementation compared to the control groups ( $\mathrm{NS}=5.1 \pm 0.2$ vs $\mathrm{CS}=8.2 \pm 0.4$ and $\mathrm{NT}=5.3 \pm 0.4$ vs $\mathrm{CT}=8.2 \pm 0.3$; both $p<0.001$ ) (Figure 7A).

On the other hand, heterogeneous immunostaining pattern of intratumor HER2-expression was observed in all tumors. Nonetheless, the mean IM score was similar in all treatment arms (SKBR3: $\mathrm{CS}=8.5 \pm 1.5, \mathrm{CT}=8.4 \pm 1.3$, $\mathrm{NS}=8.3 \pm 1.0$ and $\mathrm{NT}=8.3 \pm 0.8$; JIMT1: $\mathrm{CS}=7.3 \pm 0.9, \mathrm{CT}=$ $7.3 \pm 0.7, \mathrm{NS}=7.3 \pm 1.1$ and $\mathrm{NT}=7.3 \pm 1.4$ ) (Figure 7B).

Representative samples of the pathological examination of MUC4 and HER2 exspression levels are shown in Supplementary Figure 2. When comparing expression of MUC4 and HER2, a significant correlation was found between the presence of MUC4 and HER2 $\left(\mathrm{R}^{2}=0.53 ; p<0.001\right)$. In contrast, an inverse correlation was observed between MUC4 expression and ${ }^{89} \mathrm{Zr}$-Trastuzumab uptake $\left(\mathrm{R}^{2}=0.60\right.$; $p<0.001$ ) (Figure 8A).

Furthermore, in the trastuzumab-based treatment arms (CT and NT) a significant correlation was found between the metabolic response assessed by ${ }^{18} \mathrm{~F}-\mathrm{FDG}$ PET and HER2 accessibility for trastuzumab through

A
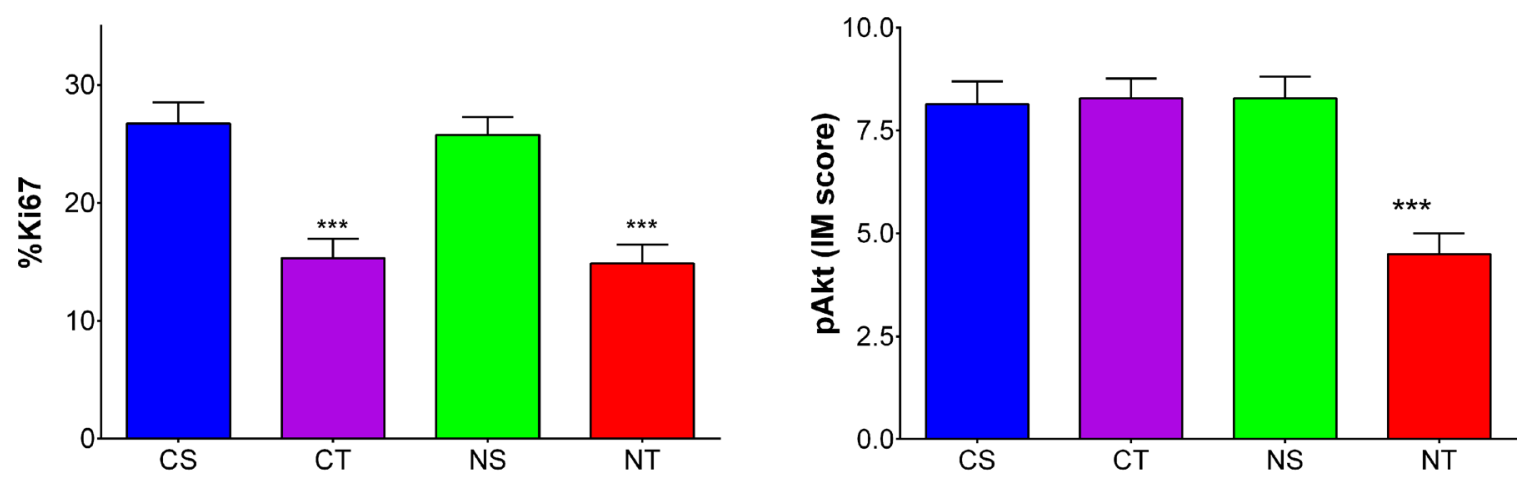

B
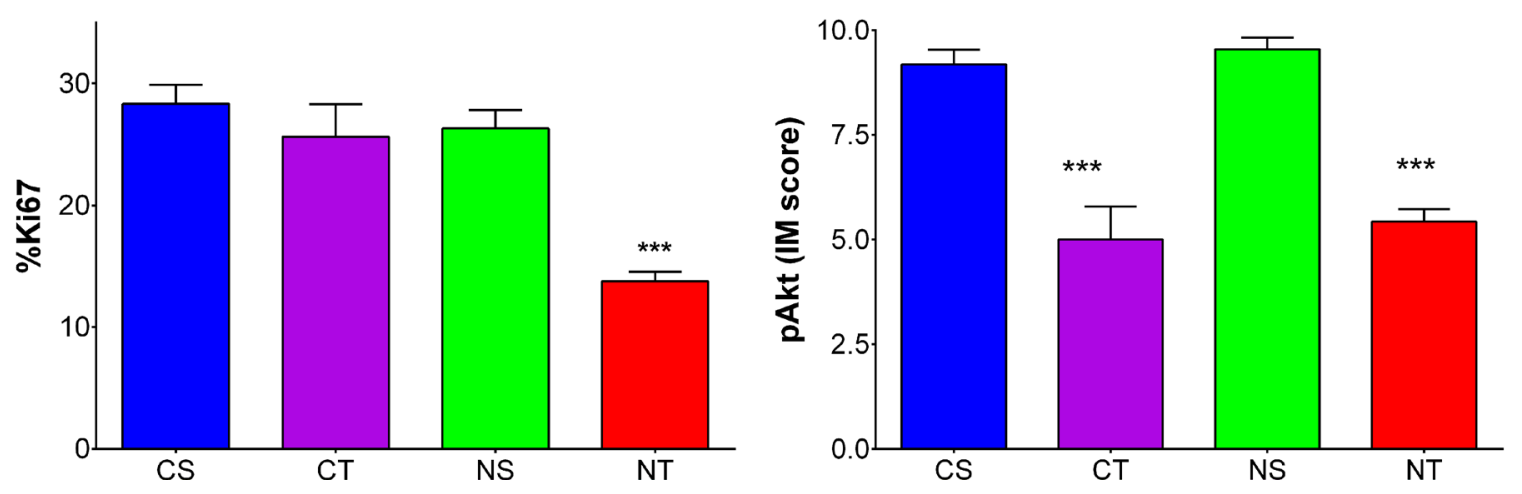

Figure 5: Combining trastuzumab with NAC supplementation reduces proliferation and activation of the molecular Pi3K/Akt signaling pathway in trastuzumab resistant tumors. proliferation index Ki67 (left) and pAkt levels (right) for (A) JIMT1 (HER2+/MUC4+) and (B) SKBr3 (HER2+/MUC4-) tumors in dual-tumor-bearing mice randomized to the four treatment arms CS (Control+Saline; blue, $n=5$ ), CT (Control+Trastuzumab; purple, $n=5)$, NS (NAC+Saline; green, $n=5)$ and NT (NAC+Trastuzumab; red $n=5$ ). Data are shown as mean \pm SEM expressed in \% positive cells for Ki67 index values and IM scores for pAkt levels with $* * * p<0.001$. 
${ }^{89} \mathrm{Zr}$-Trastuzumab PET $\left(\mathrm{R}^{2}=0.54 ; p<0.001\right)$ but not with HER2 expression $\left(\mathrm{R}^{2}<0.001 ; p=\right.$ n.s.) (Figure $\left.8 \mathrm{~B}\right)$.

\section{DISCUSSION}

This study investigated whether in tumors overexpressing HER2 and MUC4, NAC supplementation could translate into a therapeutic benefit when combined with trastuzumab. Our hypothesis was tested through different methodologies in a dual-BC-xenograft mouse model with human HER2-positive BC tumors, SKBr3 and JIMT1, the latter being resistant to trastuzumab due to MUC4 overexpression. In contrast to the trastuzumabsensitive SKBr3 tumors, JIMT1 tumors were only responsive when trastuzumab was combined with NAC supplementation. This was demonstrated by (1) an inhibition of tumor growth, (2) smaller tumor volumes as assessed by caliper and CT measurements, (3) a lower ${ }^{18}$ F-FDG accumulation, (4) a smaller Ki67 proliferation index and (5) a lower Akt phosphorylation for mice receiving the NAC-trastuzumab combination.
All these results converge to the same finding that NAC supplementation can significantly break MUC4related resistance to trastuzumab by restoring HER2 hampered accessibility.

Our previous study demonstrated that for MUC4 overexpressing tumors HER2 hampered accessibility could be improved as a result of NAC administration [19]. Once more, enhanced accessibility of trastuzumab to HER2 was shown with a $30 \%$ higher ${ }^{89} \mathrm{Zr}$-Trastuzumab uptake in JIMT1 (HER2+/MUC4+; resistant to trastuzumab) tumors exposed to NAC compared to control mice, without any effect on SKBr3 (HER2+/MUC4-; control sensitive to trastuzumab). Additionally, this study confirmed the effect of NAC on MUC4 specifically, with lower MUC4 expression of JIMT1 tumors in the NAC supplementation groups. Besides consistency with our previously published data, these findings confirm the validity of our model and approach in enhancing the accessibility of HER2 for trastuzumab by decreasing MUC4 related hindrance with mucolytic drug NAC.

In accordance with previously published data [23-25], the $\mathrm{SKBr} 3$ tumors that served as control were trastuzumab

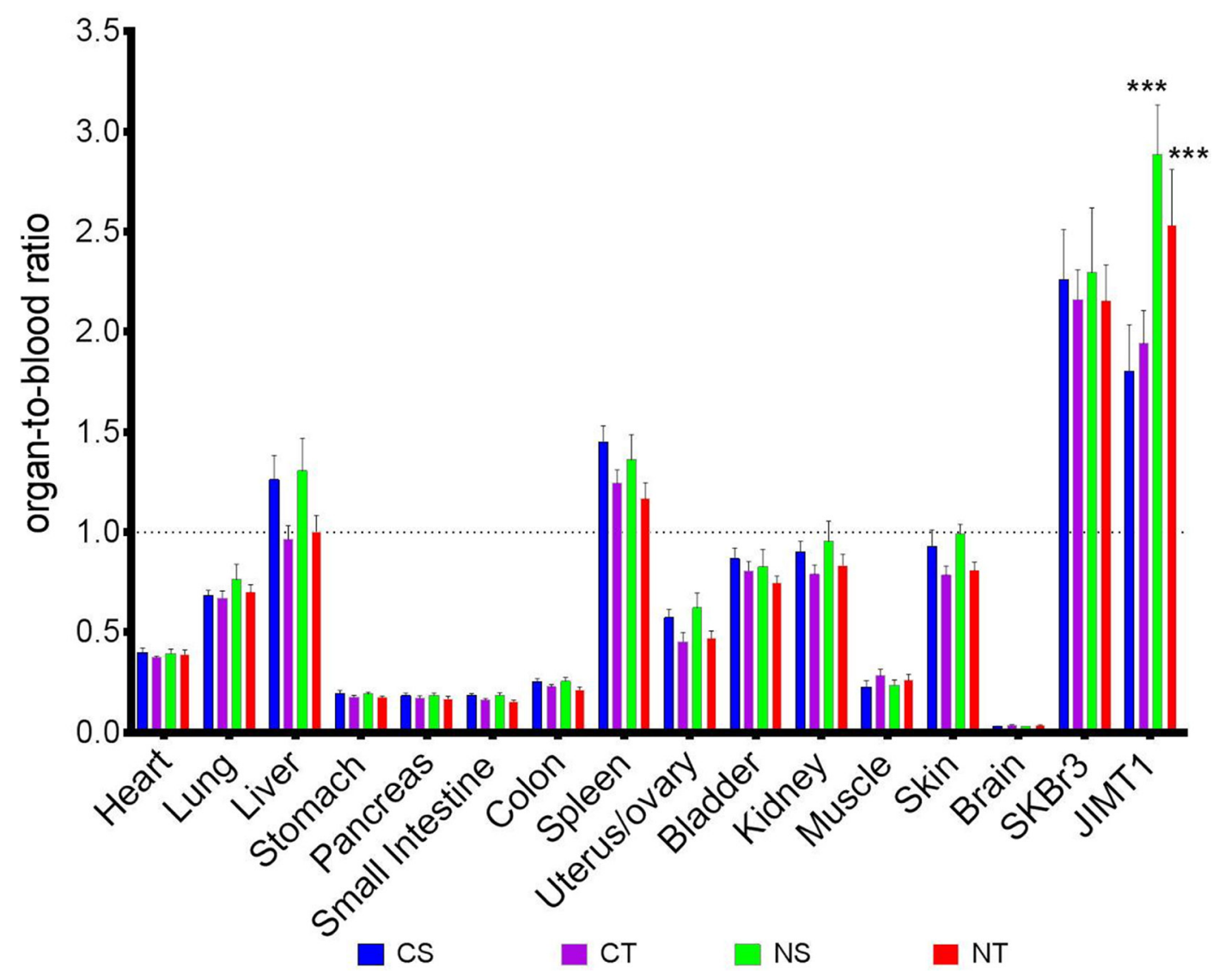

Figure 6: Prolonged NAC supplementation does not alter ${ }^{89} \mathrm{Zr}$-Trastuzumab body distribution, with the exception of the maintained enhanced uptake in MUC4-overexpressing tumors. Ex vivo body distribution of ${ }^{89} \mathrm{Zr}$-Trastuzumab uptake in JIMT1 (HER2+/MUC4+) and SKBr3 (HER2+/MUC4-) tumors in dual-tumor-bearing mice randomized to the four treatment arms CS (Control+Saline; blue, $n=10$ ), CT (Control+Trastuzumab; purple, $n=10$ ), NS (NAC+Saline; green, $n=9$ ) and NT (NAC+Trastuzumab; red $n=10)$. Data are expressed in organ-to-blood ratio and represented as mean \pm SEM with $* * * p<0.001$. 
sensitive and presented about 50\% inhibition of tumor growth under trastuzumab treatment irrespective of NAC supplementation. In contrast, for the trastuzumab resistant JIMT1 tumors, a significant anti-proliferative effect was seen only when trastuzumab was combined with NAC with a $60 \%$ slower tumor doubling time. Consistent tumor volume results were found with $\mathrm{CT}$ measurements showing halved tumor volumes in both trastuzumab treatment groups (with or without NAC) for SKBR3 and only in the trastuzumabNAC arm for JIMT1 tumors when compared to control. Also, the ex vivo measure of tumor weight at dissection validated both results with two times smaller tumors. Trastuzumab did not result in tumor shrinkage/regression but resulted in a change in growth rate. Nevertheless the effect of targeted drugs on the rate of tumor growth have been reported to be more predictive of treatment response rather than tumor shrinkage/regression [27].

Interestingly, the observed overlap at baseline seen in ${ }^{89} \mathrm{Zr}$-Trastuzumab uptake of JIMT1 tumors of mice in the NAC and control group was not mirrored in terms of trastuzumab's therapeutic response. This is probably due to the fact that the effect of NAC on MUC4 positive tumors increased over time. Accordingly, at dissection, after 60 days of NAC supplementation, the difference in ${ }^{89} \mathrm{Zr}$-Trastuzumab uptake between the two groups was twice the one observed at baseline.

PET imaging with ${ }^{18} \mathrm{~F}-\mathrm{FDG}$, a radioactive analog of glucose, was also implemented. Although all methods of therapy monitoring were concordant, the unequivocal discrimination observed between treatment arms was more pronounced when monitored by ${ }^{18} \mathrm{~F}-\mathrm{FDG}-\mathrm{PET}$. A 6-fold lesser accumulation of ${ }^{18} \mathrm{~F}-\mathrm{FDG}$ was found in both trastuzumab groups for SKBR3 and only in the trastuzumab-NAC arm for JIMT1 tumors when compared to control. Also, a significant correlation was found between ${ }^{18} \mathrm{~F}$-FDG uptake and the number of $\mathrm{Ki} 67$ positive cells $\left(\mathrm{R}^{2}=0.79, p<0.05\right.$, data not shown), supporting ${ }^{18} \mathrm{~F}$-FDG-PET as a good surrogate for tumor proliferation activity in ductal breast carcinoma [28], corresponding to the BC cells in our model. Unfortunately an absolute decrease in $\mathrm{SUV}_{\text {max }}$ after therapy could not be demonstrated. This was most likely due to tumor growth (up to $40 \%$ ) in the interval between the baseline ${ }^{18}$ F-FDG-PET and the start of the trastuzumab to allow the ${ }^{89} \mathrm{Zr}$-Trastuzumab PET examination. This issue was also previously described in clinical setting by our group [29].
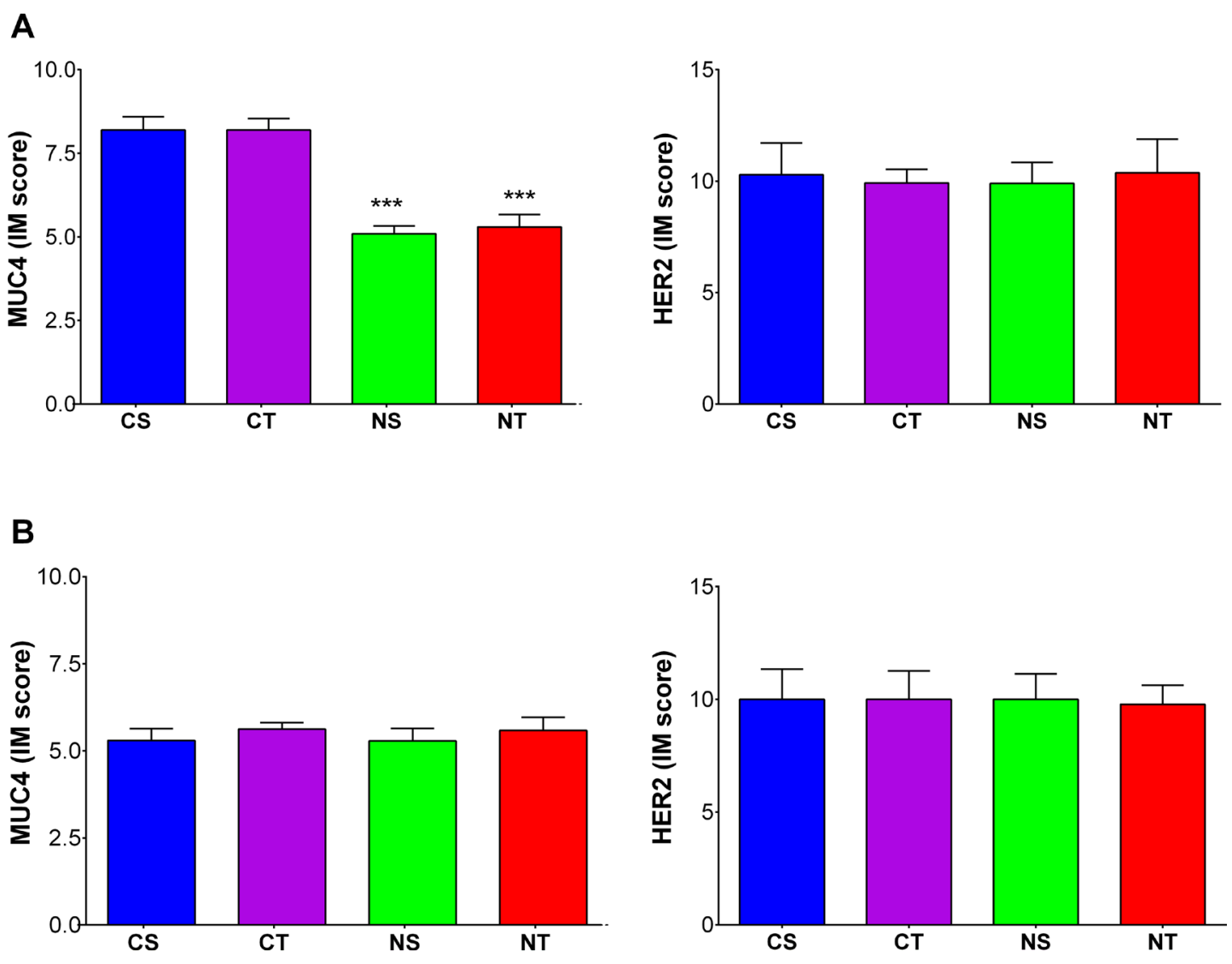

Figure 7: NAC supplementation reduces MUC4 expression in MUC4 overexpressing tumors and HER2 expression is not altered in the different treatment arms. MUC4 (left) and HER2 (right) expression levels in (A) JIMT1 (HER2+/MUC4+) and (B) SKBr3 (HER2+/MUC4-) tumors in dual-tumor-bearing mice randomized to the four treatment arms CS (Control+Saline; blue, $n=5$ ), CT (Control+Trastuzumab; purple, $n=5)$, NS (NAC+Saline; green, $n=5$ ) and NT (NAC+Trastuzumab; red $n=5$ ). Data are shown as mean \pm SEM expressed in IM scores with $* * * p<0.001$. 
The efficacy of trastuzumab treatment results mostly from the inhibition of the phosphorylation of HER2, hence and foremost the downstream PI3K-Akt pathway [6], which plays a critical role in growth factor-induced cell proliferation and survival [30]. Accordingly in our study, Akt phosphorylation was found significantly decreased in tumors responding to trastuzumab (alone for SKBr3 or only in combination with NAC for JIMT1).

The clinical importance of the $\mathrm{Ki} 67$ value in HER2 positive BC has previously been investigated. Studies showed that a Ki67 value $\leq 20 \%$ was predictive of pathological complete response [31] and associated with significantly higher post-recurrence survival [32]. In our study, the Ki67 proliferation index was significantly lowered in both trastuzumab treatment groups for SKBR3 and only in the trastuzumab-NAC
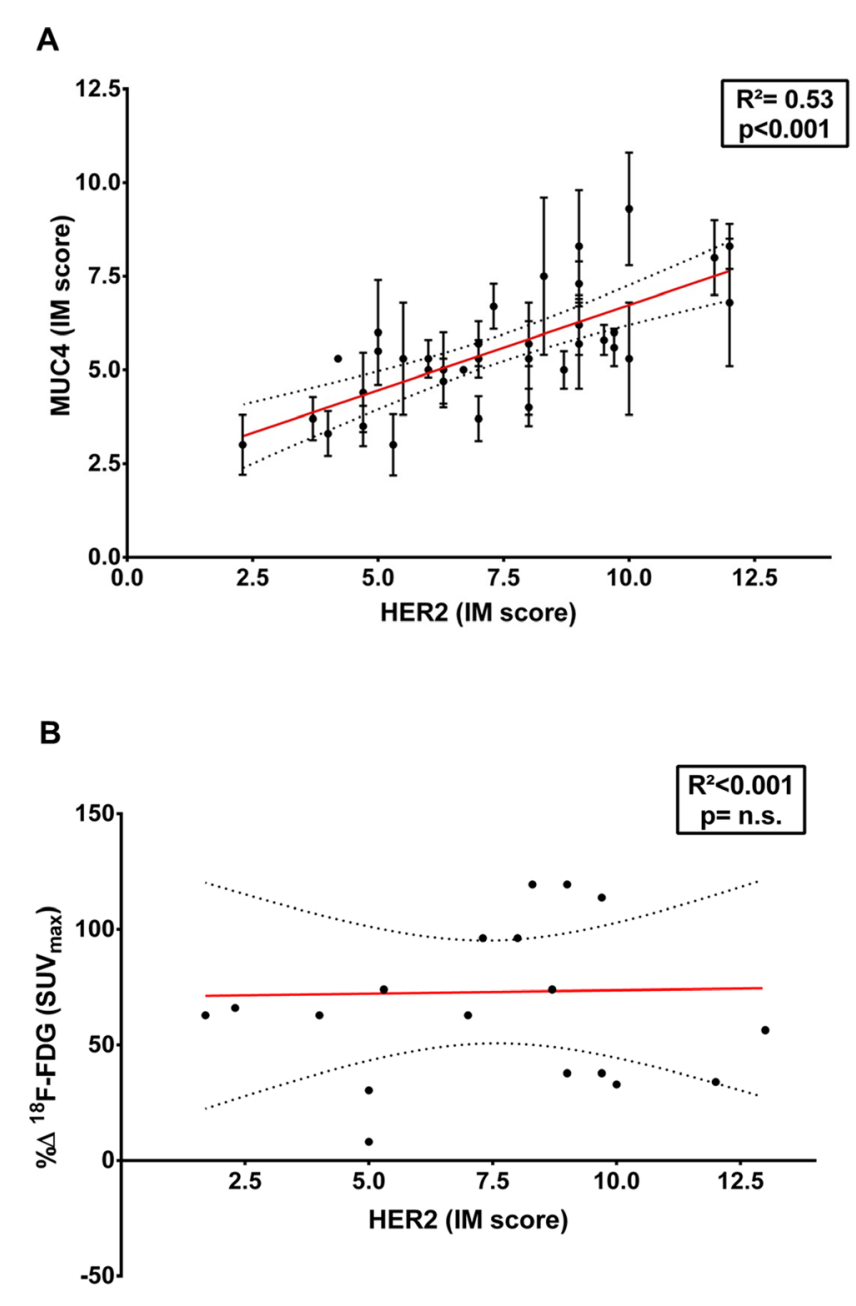

arm for JIMT1 tumors, dropping to a value below $15 \%$. Trastzumab has also been reported to exerts its effect through HER2 downregulation, this effect was not demonstrated here most likely due to heterogeneity in HER2 staining [33].

HER2 immunostaining in our study was done using a clinically available and FDA approved IHC kit with a $\mathrm{mAb}$ recognizing the intracellular domain of HER2 (ICD) [26]; whereas immunoPET (and treatment) where based on trastuzumab raised against the extracellular domain (i.e. ECD IV). This epitope difference could explain the non-concordance found between HER2 IHC and ${ }^{89} \mathrm{Zr}$ Trastuzumab immunoPET in regards to the level of MUC4 as well as the therapeutic effect of trastuzumab.

In the present study we found an inverse correlation between MUC4 expression and ${ }^{89} \mathrm{Zr}$-Trastuzumab
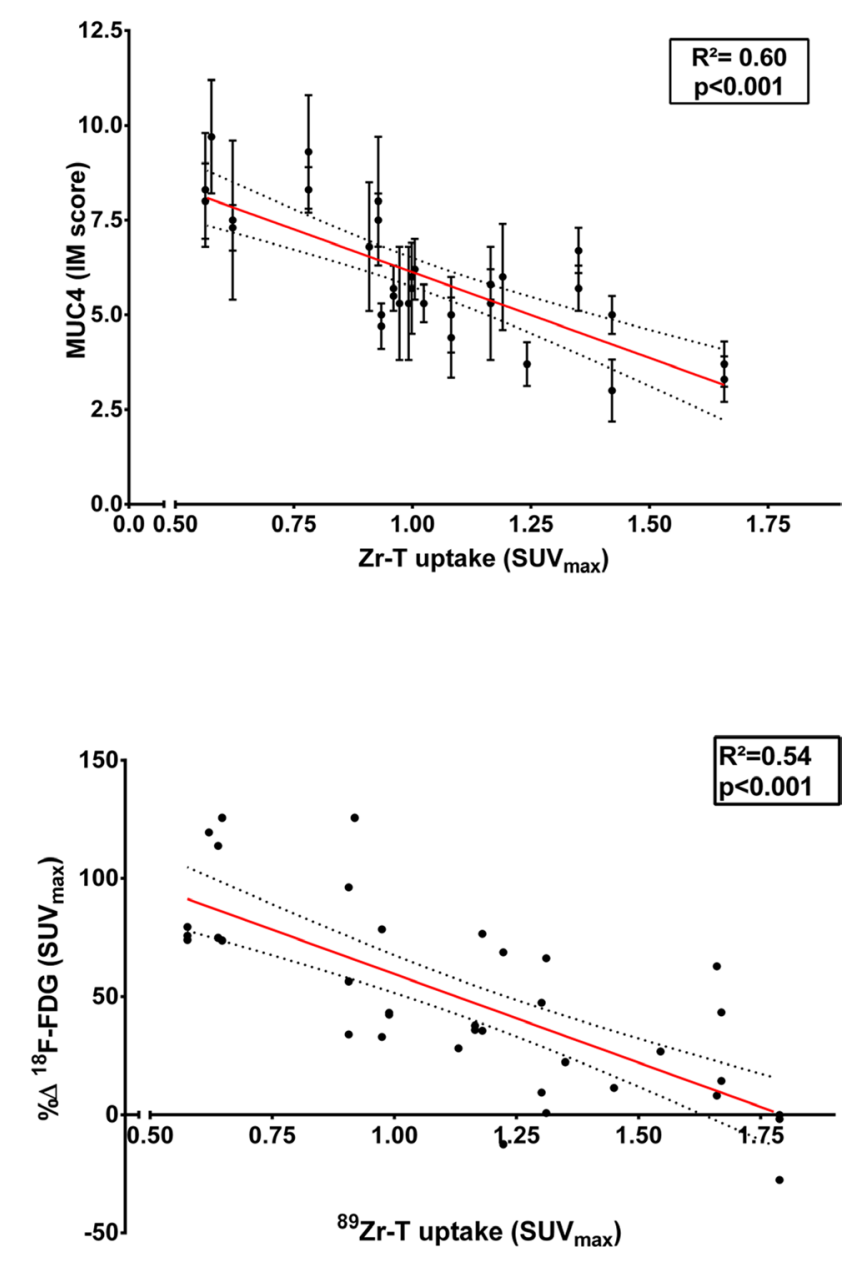

Figure 8: HER2 expression on immunostaining and HER2 accessibility on ${ }^{89} \mathrm{Zr}$-Trastuzumab PET are not concordant in regards to their association with MUC4 or metabolic change on ${ }^{18} \mathbf{F}$-FDG. The side by side comparison of the association of HER2 expression levels ( left) and ${ }^{89} \mathrm{Zr}$-Trastuzumab uptake (right) with (A) MUC4 is shown including both JIMT1 (HER2+/MUC4+) and SKBr3 (HER2+/MUC4-) tumors in dual-tumor-bearing mice randomized to the four treatment arms CS (Control+Saline), CT (Control+Trastuzumab), NS (NAC+Saline) and NT (NAC+Trastuzumab). (B) The side by side comparison of the association to ${ }^{18} \mathrm{~F}-\mathrm{FDG}$ PET metabolic response is limited to mice randomized to the trastuzumab treatment arms CT and NT are also represented. Data shown include both tumor types and are expressed in IM scores for HER2 and MUC4 expression, in $\mathrm{SUV}_{\max }$ for ${ }^{89} \mathrm{Zr}$-Trastuzumab uptake and expressed as the percentage difference in $\mathrm{SUV}_{\max }\left(\% \Delta S U V_{\max }\right)$ for ${ }^{18} \mathrm{~F}-\mathrm{FDG}$ metabolic response. 
immunoPET in contrast with a positive correlation with HER2 IHC. Although seemingly contradictory, ${ }^{89} \mathrm{Zr}$-Trastuzumab findings are concordant with MUC4 hindering the accessibility of HER2-ECD henceforth the binding of (radiolabeled) trastuzumab [14, 19], while the HER2 IHC results are agreeing with MUC4 as modulator of the expression of HER2 [17, 18].

This further implies that tumors that would benefit of trastuzumab (or TDM1) are not necessarily the ones with the highest density of HER2, as they also might be the ones with the highest expression of MUC4. On the other hand, these tumors represent the ideal candidates for combining trastuzumab (or T-DM1) with NAC supplementation and as a result be the most favored by our proposed approach.

In addition, a significant correlation was found between ${ }^{89} \mathrm{Zr}$-Trastuzumab immunoPET (ECD) and the metabolic response after trastuzumab treatment assessed by ${ }^{18} \mathrm{~F}$-FDG PET and not with HER2 expression (ICD).

This relationship between a specific HER2 domain and response to trastuzumab based treatment has also been demonstrated in clinical studies.

Recently, a clinical study on 180 HER2-positive patients under trastuzumab treatment explored the relationship between domain-specific HER2 expression of the tumor on IHC and the benefit of treatment for the patient in terms of disease-free survival (DFS). CarvajalHausdorf et al. revealed a differential benefit from trastuzumab therapy based on HER2 ECD expression rather than ICD in BC [35]. Similarly, our group demonstrated that ${ }^{89} \mathrm{Zr}$-Trastuzumab immunoPET (ECD) before treatment allowed the discrimination of patients benefiting from trastuzumab emtansine (T-DM1) with longer time to treatment failure, rather than their HER2 status (ICD/FISH) [29]. Both findings strongly advocate for a shift to an analysis of HER2 ECD rather than the currently used ICD when determining the eligibility of a patient for a targeted treatment against the ECD.

The present study is in concordance and further shows that increasing the amount of accessible HER2ECD with NAC (on ${ }^{89} \mathrm{Zr}$-Trastuzumab), results in an increased therapeutic benefit of trastuzumab regardless of HER2-ICD (on IHC). Furthermore, our results imply that, despite an intact ICD expression, the benefit of trastuzumab-based treatment is greatly diluted when the tumor lesion presents with impaired accessibility to HER2 ECD. Henceforth, NAC supplementation could be of help in those circumstances. It could enhance the amount of available ECD without compromising the therapeutic effect of trastuzumab.

These issues of target accessibility are now even more critical with the advent of new antibody drug conjugates given as single agents, as certain mAbs might be inherently suboptimal for targeted drug delivery due to less accessible target ECD epitopes. Ergo, a possible course of action could be (1) opting for an $\mathrm{mAb}$ recognizing a more accessible membrane distal epitope, such as pertuzumab (ECD II [29]) which might represent a superior option for targeted drug delivery to HER2 rather than trastuzumab's ECD IV (eg. T-DM1) or (2) attempt to enhance the accessibility of the epitope for the $\mathrm{mAb}$ in question as proposed in this study.

The present study highlighted the potential role of molecular imaging with radiolabeled trastuzumab in gaining information regarding trastuzumab-HER2 interaction, in the investigation of a particular resistance mechanism and as a potential biomarker for response prediction. Although, our study focused on the already longstanding HER2-treatment trastuzumab, the same interactions with HER2 are expected for trastuzumab based treatments such as T-DM1. The latter is now widely offered and has in part substituted trastuzumab in the treatment of HER2 positive BC patients. Nonetheless, up to this day, T-DM1 administration is still preceeded by trastuzumab and also follows when resistance to the former arises. Hence, ways to possibly overcome resistance to trastuzumab remain highly relevant.

Taken together, our results demonstrate that NAC supplementation can significantly break MUC4-related resistance to trastuzumab by restoring HER2 hampered accessibility. The effect was revealed on ${ }^{89} \mathrm{Zr}$-Trastuzumab HER2-immunoPET, monitored by ${ }^{18} \mathrm{~F}-\mathrm{FDG}-\mathrm{PET} / \mathrm{CT}$ and tumor volume measurements, and validated at the molecular level. Tentatively, this safe and promising approach may be offered to a subset of patients with HER2-positive BC tumors overexpressing mucins.

\section{MATERIALS AND METHODS}

\section{${ }^{89} \mathrm{Zr}$-labeling of trastuzumab}

Labeling of trastuzumab and quality controls were performed as previously described [19]: $2.5 \mathrm{mg}$ of GMP grade N-SucDF-trastuzumab (VU Windesheim-VU Medisch Centrum, Amsterdam, Holland), synthesized by coupling desferrioxamine to trastuzumab, was radiolabeled with $111 \mathrm{MBq}^{89} \mathrm{Zr}$-oxalate $\left(\mathrm{t}_{1 / 2}=78.4 \mathrm{~h}\right.$; Perkin Elmer). The specific activity was adjusted to $3.7 \mathrm{MBq} / 100 \mu \mathrm{g} / 100 \mu \mathrm{L}$ by adding unlabeled trastuzumab.

\section{Measurement of ${ }^{89} \mathrm{Zr}$ radioactivity}

${ }^{89} \mathrm{Zr}$-Trastuzumab accumulated activity was measured in a gamma-counter (Wallac Wizard, PerkinElmer) with background- and decay-correction as well as reference activity standards of $10 \%, 20 \%$ and $30 \%$ of the administered radioactivity.

\section{Cells}

The human BC HER2-positive and MUC4negative SKBr3 (ATCC) and HER2-positive and MUC4- 
positive JIMT1 (DSMZ) were cultured in DMEM high glucose (Lonza), supplemented with heat inactivated 10\% FBS (Fisher) and antibiotics (penicillin-G (Sigma), streptomycin sulphate and kanamycine (both from Gentaur)) at $37^{\circ} \mathrm{C}$ and $5 \% \mathrm{CO}_{2}$ in a fully humidified atmosphere. Cells were subcultured twice a week.

Cells were regularly checked for mycoplasma contamination using MycoAlert ${ }^{\circledR}$ Mycoplasma Detection Kit (Lonza).

\section{Mouse model}

Six-week-old athymic nu/nu female mice (Charles River) were inoculated subcutaneously on the right posterior leg with $3 \times 10^{6} \mathrm{SKBr} 3$ cells and on the left with $1.5 \times 10^{6}$ JIMT1 cells suspended in $100 \mu \mathrm{L}$ of DMEM and Basement Membrane Extract (1:1; Cultrex, Trevigen). Imaging and treatments (Figure 1) were initiated two weeks after inoculation when tumors reached approximately $0.5 \mathrm{~cm}^{3}$. Mice were randomized to four different groups: (1) the CS group receiving sweetened drinking water and i.p. saline injections $(n=10)$, (2) the CT group receiving sweetened drinking water and trastuzumab injections (i.p., $5 \mathrm{mg} / \mathrm{kg}[37,38])(n=10)$, (3) the NS group receiving sweetened drinking water supplemented with NAC and saline i.p. injections $(n=9)$, and (4) the NT group receiving sweetened drinking water supplemented with NAC and trastuzumab injections (i.p., $5 \mathrm{mg} / \mathrm{kg})(n=10)$.

The drinking bottles were sweetened and refreshed twice a week until sacrifice for all groups. The drinking water of group NS and NT was supplemented with $4 \mathrm{~g} / \mathrm{L}$ NAC (Sigma Aldrich) and adjusted to $\mathrm{pH}$ 6.5-7.5 with sodium hydroxide $[39,40]$. NAC supplemented in this manner resulted in a mean dose of $1 \mathrm{~g}$ of NAC per $\mathrm{kg}$ body weight per day [39].

Mice were observed daily for signs of discomfort or mortality throughout the treatment period and body weight was recorded weekly. All animal experiments were reviewed and approved by the Committee on Animal Ethics and Well Being of the Université Libre de Bruxelles (protocol 495N).

\section{Tumor growth}

Tumor growth was monitored weekly by caliper measurements until sacrifice. Tumor volume was calculated using formula $\frac{\pi}{6} \times \sqrt[2]{(L W)^{3}}$ and later compared to the volume determined on computed tomography images.

\section{Small-animal PET-CT imaging}

Studies were conducted using a $\mu$ PET-CT (nanoScan ${ }^{\circledR} \mathrm{PET} / \mathrm{CT}$, Mediso) on dual-tumor-bearing mice ( $n=9-10 /$ group). Each mouse was scanned three times, with an ${ }^{18} \mathrm{~F}$-FDG and ${ }^{89} \mathrm{Zr}$-Trastuzumab PET-CT before treatment and an ${ }^{18} \mathrm{~F}$-FDG PET-CT post treatment (Figure 1). The PET tracer $\left({ }^{18} \mathrm{~F}-\mathrm{FDG}=4.14 \pm 0.36 \mathrm{MBq}\right.$; ${ }^{89} \mathrm{Zr}$-Trastuzumab $=3.15 \pm 0.24 \mathrm{MBq} / 100 \mu \mathrm{L}$ ) was injected in a lateral tail vein. Images were recorded for ${ }^{18} \mathrm{~F}$-FDG at $1 \mathrm{~h}$ and ${ }^{89} \mathrm{Zr}$-Trastuzumab 6 days after injection respectively. Two animals were scanned simultaneously under isoflurane anesthesia (induction: $3 \%$ isoflurane, $3 \mathrm{~L}$ $\mathrm{O}_{2}$; maintenance: $1.5 \%$ isoflurane, $1.5 \mathrm{~L} \mathrm{O}_{2}$ ) and at $37^{\circ} \mathrm{C}$ using a thermoregulation unit (Minerve).

Baseline ${ }^{18} \mathrm{~F}-\mathrm{FDG}$ PET showed homogenous and similar radiotracer uptake in all tumors and in all mice. The subsequent randomization was well balanced, with similar tumor ${ }^{18} \mathrm{~F}-\mathrm{FDG}$ uptakes for the different arms prior to treatment in both types $\left(\mathrm{SUV}_{\max }: \mathrm{SKBR} 3\right.$ : $\mathrm{CS}=0.61 \pm 0.06, \mathrm{CT}=0.62 \pm 0.06, \mathrm{NS}=0.60 \pm 0.05$ and $\mathrm{NT}=0.64 \pm 0.08 ; \mathrm{JIMT} 1: \mathrm{CS}=0.69 \pm 0.07, \mathrm{CT}=0.56 \pm 0.04$, $\mathrm{NS}=0.66 \pm 0.06$ and $\mathrm{NT}=0.70 \pm 0.07$ ).

\section{Ex-vivo body distribution}

After the last scan, at 6 days post ${ }^{89} \mathrm{Zr}$-Trastuzumab administration, animals were euthanized by cervical dislocation under anesthesia and an ex-vivo body distribution study was performed. ${ }^{89} \mathrm{Zr}$-Trastuzumab activity was measured in 16 organs (including tumors). Tissue uptake is presented as organ to blood ratio.

\section{Immunostaining}

After dissection, tumors were immediately fixed in $10 \%$ formalin until the ex-vivo study was performed and radioactivity decayed. Samples were then transferred to $70 \%$ ethanol and stored at $4{ }^{\circ} \mathrm{C}$. Samples were processed and embedded in paraffin, and $4-\mu \mathrm{m}$ sections were prepared for HE-staining. Tumor sections from a subset of animals from each cohort were also analyzed using immunostaining with different antibodies: anti-HER2 (4B5, Roche), anti-MUC4 (8G-7, Biocare Medical) antipAkt (D9E, Santa Cruz) and Ki67 (MIB-1, Dako) and subsequently stained with diaminobensidine (DAB, iview DAB detection kit, Ventana) except for pAkt staining where alkaline phosphatase red (ultraView Universal Alkaline Phosphatase Red, Ventana) was used.

Stained sections were imaged using NDP Slice Scanner (Hamamatsu). Three regions were selected at random on different part of the section and analyzed at $\times 20$ magnification, using ImmunoMembrane and ImmunoRatio web applications. In brief, ImmunoMembrane software segments stained membrane regions from the user-submitted sample image and classifies the image into $0 / 1+, 2+$, or $3+$ and calculates IM scores based on the membrane staining completeness and intensity; whereas, ImmunoRatio software segments DAB-stained and HE-stained nuclei regions from the user-submitted image and calculates the percentage 
of DABstained nuclear area over total nuclear area. Both applications generate a pseudo-colored overlay images matching the area segmentation [41].

\section{PET-CT image analysis}

PET-CT image analysis and quantification were performed using PMOD software (PMOD Technologies, Switzerland). To define the volumes of interest (VOIs), tumors were manually contoured on the CT image. To quantify radioactivity within the tumor corresponding PET uptake values were normalized to the injected radioactivity per body weight (SUV).

The results are represented as the tumor volume for $\mathrm{CT}$ and the maximum uptake value of the VOI $\left(\mathrm{SUV}_{\text {max }}\right)$ for PET. Changes in ${ }^{18} \mathrm{~F}-\mathrm{FDG}$ uptake after tumor growth under the different treatment regimens are represented as the percentage difference between $\mathrm{SUV}_{\text {max }}$ post-treatment and $\mathrm{SUV}_{\max }$ pre-treatment $\left(\% \Delta \mathrm{SUV}_{\max }\right)$. Lower $\% \Delta \mathrm{SUV}_{\max }$ denoted lower tumor glucose metabolism in comparisons between treatment regimens.

\section{Statistics}

Statistical analysis was done using ANOVA for the 4 animal group differences, student-T test when comparing two data replicates, extra sum-of-squares $F$ test for curve differences, Pearson test for correlation. Statistics and graphs were performed using Graphpad Prism (GraphPad Software, San Diego, CA, USA). Data are presented as mean \pm standard error of the mean (SEM) unless stated otherwise.

\section{ACKNOWLEDGMENTS AND FUNDING}

We express our gratitude to "Les Amis de Bordet" and "Fonds Gaston Ithier" for the grants obtained to conduct this study. We thank the nuMix team of the Center for Microscopy and Molecular Imaging (CMMI) for their assistance in the animal experiment work.

\section{CONFLICTS OF INTEREST}

The authors declare no conflicts of interest.

\section{REFERENCES}

1. Sergina NV, Moasser MM. The HER family and cancer: emerging molecular mechanisms and therapeutic targets. Trends Mol Med. 2007; 13:527-34.

2. Bailey TA, Luan H, Clubb RJ, Naramura M, Band V, Raja SM, Band H. Mechanisms of Trastuzumab resistance in ErbB2-driven breast cancer and newer opportunities to overcome therapy resistance. J Carcinog. 2011; 10:28.

3. Schechter AL, Stern DF, Vaidyanathan L, Decker SJ, Drebin JA, Greene MI, Weinberg RA. The neu oncogene: an erb-B-related gene encoding a $185,000-\mathrm{Mr}$ tumour antigen. Nature. 1984; 312:513-6.

4. Slamon DJ, Clark GM, Wong SG, Levin WJ, Ullrich A, McGuire WL. Human breast cancer: correlation of relapse and survival with amplification of the HER-2/neu oncogene. Science. 1987; 235:177-82.

5. Junttila TT, Akita RW, Parsons K, Fields C, Lewis Phillips GD, Friedman LS, Sampath D, Sliwkowski MX. Ligand-Independent HER2/HER3/PI3K Complex Is Disrupted by Trastuzumab and Is Effectively Inhibited by the PI3K Inhibitor GDC-0941. Cancer Cell. 2009; 15:429-40.

6. Yakes FM, Chinratanalab W, Ritter CA, King W, Seelig S, Arteaga CL. Herceptin-induced Inhibition of Phosphatidylinositol-3 Kinase and Akt Is Required for Antibody-mediated Effects on p27, Cyclin D1, and Antitumor Action. Cancer Res. 2002; 62:4132-41.

7. Davoli A, Hocevar BA, Brown TL. Progression and treatment of HER2-positive breast cancer. Cancer Chemother Pharmacol. 2010; 65:611-23.

8. Mitri Z, Constantine T, O'Regan R. The HER2 Receptor in Breast Cancer: Pathophysiology, Clinical Use, and New Advances in Therapy. Chemother Res Pract. 2012; 2012:743193.

9. Mukohara T. Mechanisms of resistance to anti-human epidermal growth factor receptor 2 agents in breast cancer. Cancer Sci. 2011; 102:1-8.

10. Pohlmann PR, Mayer IA, Mernaugh R. Resistance to Trastuzumab in Breast Cancer. Clin Cancer Res. 2009; 15:7479-91.

11. Mukhopadhyay P, Chakraborty S, Ponnusamy MP, Lakshmanan I, Jain M, Batra SK. Mucins in the pathogenesis of breast cancer: implications in diagnosis, prognosis and therapy. Biochim Biophys Acta. 2011; 1815:224-40.

12. Carraway KL, Price-Schiavi SA, Komatsu M, Jepson S, Perez A, Carraway CA. Muc4/sialomucin complex in the mammary gland and breast cancer. J Mammary Gland Biol Neoplasia. 2001; 6:323-37.

13. Workman HC, Miller JK, Ingalla EQ, Kaur RP, Yamamoto DI, Beckett LA, Young LJ, Cardiff RD, Borowsky AD, Carraway KL, Sweeney C, Carraway KL. The membrane mucin MUC4 is elevated in breast tumor lymph node metastases relative to matched primary tumors and confers aggressive properties to breast cancer cells. Breast Cancer Res. 2009; 11:R70.

14. Nagy $P$, Friedländer E, Tanner M, Kapanen AI, Carraway KL, Isola J, Jovin TM. Decreased accessibility and lack of activation of ErbB2 in JIMT-1, a herceptinresistant, MUC4-expressing breast cancer cell line. Cancer Res. 2005; 65:473-82.

15. Price-Schiavi SA, Jepson S, Li P, Arango M, Rudland PS, Yee L, Carraway KL. Rat Muc4 (sialomucin complex) reduces binding of anti-ErbB2 antibodies to tumor cell surfaces, a potential mechanism for herceptin resistance. Int J Cancer. 2002; 99:783-91. 
16. Carraway KL, Theodoropoulos G, Kozloski GA, Carothers Carraway CA. Muc4/MUC4 functions and regulation in cancer. Future Oncol. 2009; 5:1631-40.

17. Chaturvedi P, Singh AP, Chakraborty S, Chauhan SC, Bafna S, Meza JL, Singh PK, Hollingsworth MA, Mehta PP, Batra SK. MUC4 Mucin Interacts with and Stabilizes the HER2 Oncoprotein in Human Pancreatic Cancer Cells. Cancer Res. 2008; 68:2065-70.

18. Singh AP, Chaturvedi P, Batra SK. Emerging Roles of MUC4 in Cancer: A Novel Target for Diagnosis and Therapy. Cancer Res. 2007; 67:433-6.

19. Wimana Z, Gebhart $G$, Guiot $T$, Vanderlinden B, Morandini R, Doumont G, Sherer F, Simaeys GV, Goldman S, Ghanem G, Flamen P. Mucolytic Agents Can Enhance HER2 Receptor Accessibility for [89Zr] Trastuzumab, Improving HER2 Imaging in a MucinOverexpressing Breast Cancer Xenograft Mouse Model. Mol Imaging Biol. 2015; 17:697-703.

20. Cotgreave IA. N-acetylcysteine: pharmacological considerations and experimental and clinical applications. Adv Pharmacol. 1997; 38:205-27.

21. Kelly GS. Clinical applications of N-acetylcysteine. Altern Med Rev J Clin Ther. 1998; 3:114-27.

22. Schrier BP, Lichtendonk WJ, Witjes JA. The effect of $\mathrm{N}$-acetyl-L-cysteine on the viscosity of ileal neobladder mucus. World J Urol. 2002; 20:64-7.

23. Leontieva OV, Blagosklonny MV. Yeast-like chronological senescence in mammalian cells: phenomenon, mechanism and pharmacological suppression. Aging (Albany NY). 2011; 3:1078-91. https://doi.org/10.18632/aging.100402.

24. Hudziak RM, Lewis GD, Winget M, Fendly BM, Shepard HM, Ullrich A. p185HER2 monoclonal antibody has antiproliferative effects in vitro and sensitizes human breast tumor cells to tumor necrosis factor. Mol Cell Biol. 1989; 9:1165-72.

25. Tseng PH, Wang YC, Weng SC, Weng JR, Chen CS, Brueggemeier RW, Shapiro CL, Chen CY, Dunn SE, Pollak M, Chen CS. Overcoming Trastuzumab Resistance in HER2-Overexpressing Breast Cancer Cells by Using a Novel Celecoxib-Derived Phosphoinositide-Dependent Kinase-1 Inhibitor. Mol Pharmacol. 2006; 70:1534-41.

26. Longva KE, Pedersen NM, Haslekås C, Stang E, Madshus IH. Herceptin-induced inhibition of ErbB2 signaling involves reduced phosphorylation of Akt but not endocytic downregulation of ErbB2. Int J Cancer. 2005; 116:359-67.

27. Kelland LR. "Of mice and men": values and liabilities of the athymic nude mouse model in anticancer drug development. Eur J Cancer. 2004; 40:827-36.

28. Buck A, Schirrmeister H, Kühn T, Shen C, Kalker T, Kotzerke J, Dankerl A, Glatting G, Reske S, Mattfeldt T. FDG uptake in breast cancer: correlation with biological and clinical prognostic parameters. Eur J Nucl Med Mol Imaging. 2002; 29:1317-23.

29. Gebhart G, Lamberts LE, Wimana Z, Garcia C, Emonts P, Ameye L, Stroobants S, Huizing M, Aftimos P, Tol J,
Oyen WJG, Vugts DJ, Hoekstra OS, et al. Molecular imaging as a tool to investigate heterogeneity of advanced HER2-positive breast cancer and to predict patient outcome under trastuzumab emtansine (T-DM1): the ZEPHIR Trial. Ann Oncol. 2015; 27:619-24.

30. Nicholson KM, Anderson NG. The protein kinase B/Akt signalling pathway in human malignancy. Cell Signal. 2002; 14:381-95.

31. Fasching PA, Heusinger K, Haeberle L, Niklos M, Hein A, Bayer CM, Rauh C, Schulz-Wendtland R, Bani MR, Schrauder M, Kahmann L, Lux MP, Strehl JD, et al. Ki67, chemotherapy response, and prognosis in breast cancer patients receiving neoadjuvant treatment. BMC Cancer. 2011; 11:486.

32. Ibrahim T, Farolfi A, Scarpi E, Mercatali L, Medri L, Ricci M, Nanni O, Serra L, Amadori D. Hormonal receptor, human epidermal growth factor receptor-2, and Ki67 discordance between primary breast cancer and paired metastases: clinical impact. Oncology. 2013; $84: 150-7$.

33. Canonici A, Gijsen M, Mullooly M, Bennett R, Bouguern N, Pedersen K, O'Brien NA, Roxanis I, Li JL, Bridge E, Finn R, Siamon D, McGowan P, et al. Neratinib overcomes trastuzumab resistance in HER2 amplified breast cancer. Oncotarget. 2013; 4:1592-605. https://doi.org/10.18632/ oncotarget.1148.

34. Schrohl AS, Pedersen HC, Jensen SS, Nielsen SL, Brünner N. Human epidermal growth factor receptor 2 (HER2) immunoreactivity: specificity of three pharmacodiagnostic antibodies. Histopathology. 2011; 59:975-83.

35. Carvajal-Hausdorf DE, Schalper KA, Pusztai L, Psyrri A, Kalogeras KT, Kotoula V, Fountzilas G, Rimm DL. Measurement of Domain-Specific HER2 (ERBB2) Expression May Classify Benefit From Trastuzumab in Breast Cancer. J Natl Cancer Inst. 2015; 107:djv136.

36. Metzger-Filho O, Winer EP, Krop I. Pertuzumab: Optimizing HER2 Blockade. Clin Cancer Res. 2013; 19:5552-6.

37. Shi Y, Fan X, Deng H, Brezski RJ, Rycyzyn M, Jordan RE, Strohl WR, Zou Q, Zhang N, An Z. Trastuzumab Triggers Phagocytic Killing of High HER2 Cancer Cells In Vitro and In Vivo by Interaction with Fc $\gamma$ Receptors on Macrophages. J Immunol. 2015; 194:4379-86.

38. Barok M, Tanner M, Köninki K, Isola J. Trastuzumab-DM1 causes tumour growth inhibition by mitotic catastrophe in trastuzumab-resistant breast cancer cells in vivo. Breast Cancer Res. 2011; 13:R46.

39. Clark J, Clore EL, Zheng K, Adame A, Masliah E, Simon DK. Oral N-acetyl-cysteine attenuates loss of dopaminergic terminals in alpha-synuclein overexpressing mice. PloS One. 2010; 5:e12333.

40. Marian AJ, Senthil V, Chen SN, Lombardi R. Antifibrotic Effects of Antioxidant N-Acetylcysteine in a Mouse Model 
of Human Hypertrophic Cardiomyopathy Mutation. J Am Coll Cardiol. 2006; 47:827-34.

41. Tuominen VJ, Tolonen TT, Isola J. ImmunoMembrane: a publicly available web application for digital image analysis of HER2 immunohistochemistry. Histopathology. 2012; 60:758-67. 